\title{
Urgences
}

\section{Donald Aspirot, Le village intérieur,Saint-Anaclet, Éditions Jonathan, coll." Au pied de la lettre ", 1981, 126 p.}

\section{Marie Bélisle}

Numéro 2, 3e trimestre 1981

URI : https://id.erudit.org/iderudit/025034ar

DOI : https://doi.org/10.7202/025034ar

Aller au sommaire du numéro

Éditeur(s)

Urgences

ISSN

0226-9554 (imprimé)

1927-3924 (numérique)

Découvrir la revue

Citer ce compte rendu

Bélisle, M. (1981). Compte rendu de [Donald Aspirot, Le village intérieur,Saint-Anaclet, Éditions Jonathan, coll. " Au pied de la lettre ", 1981, 126

p.] Urgences, (2), 85-86. https://doi.org/10.7202/025034ar d'utilisation que vous pouvez consulter en ligne.

https://apropos.erudit.org/fr/usagers/politique-dutilisation/ 


\section{LE VILLAGE INTERIEUR, de Donald Aspirot}

Aspirot, Donald, Le village intérieur, éditions Jonathan, 1981. (Collection "Au pied de la lettre"). 126 pages. Préface de Jacques Daignault.

"Est-ce un village intérieur?

Suis-je l'unique esthéticien

De mes longs horizons

Et de tous ces poèmes

(...)

Est-ce un village intérieur?

Ou est-ce mon crâne habité

Par des maisonnettes

Ou par quelques proses..." (1)

C'est par cette interrogation que Donald Aspirot nous fait entrer dans son monde poétique, posant, dès les premières pages, les couleurs qu'on retrouvera dans l'ensemble du recueil: la mer, les maisons, les souvenirs, annonçant presque les variations de style: poèmes, chansons, prose.

En effet, dans ce long recueil, l'auteur amène le lecteur à visiter, à traverser son village; l'itinéraire qu'il nous propose nous fera passer de l'Asile à l'Eden, nous fera voir l'Ombre, l'Auberge, l'Enceinte. Les sensations sont multiples, le ton se fait parfois grave, parfois ironique. Souvent pointe un brin de nostalgie. Le village intérieur constitue en quelque sorte, un journal poétique où on apprend à connaitre la Baiedes-Chaleurs, dont lauteur est originaire, Matane aussi, où il a vécu, un journal poétique où sont présentes l'amie et la fille de Donald Aspirot, particulièrement dans la troisième partie du recueil: L'Enceinte.

Du point de vue du style, Le village intérieur est d'inspiration surtout "traditionnelle", en ce sens que les textes qui le composent ont souvent un rythme régulier et s'écartent rarement des normes d'écriture. Bref, une éeriture qui étonne peu, qui demeure relativement accessible, même pour ceux qui n'ont pas "l'habitude de la poésie". Par ailleurs, sou- 
lignons que dans plusieurs cas, il s'agit de textes de chansons, ce qui explique sans doute, en partie, la régularité du rythme et la relative simplicité des images. "Les mots dansent mais avec une prudence extrême afin que l'ivresse du vertige ne fasse qu'émouvoir... sans faire chavirer". (2)

Marie Bélisle

(1) p. 11

(2) p. 6

LE DÉPART DU GRAND HIBOU BLANC, de Gérald Tremblay

De St-Léandre nous est parvenu, à la fin d'avril 81 , un beau cadeau comme sait si bien le faire la Nature Gaspésienne: un recueil de poèmes, contes, dessins et photos signé Gérald Tremblay et intitulé "Le départ du Grand Hibou Blane". Un livre d'une cinquantaine de pages, tíré à 100 exemplaires, tous numérotés, et publié à compte d'auteur. Le procédé d'impression ressemble à de la photocopie, mais de bien meilleure qualité; la couverture est imprimée sur un carton bleu-ciel-gaspésien et s'orne d'un dessin original de Claude Bernier. L'ensemble est harmonieusement agencé et définitivement fait avec amour. C'est un livre que je n'ai pu m'empêcher de feuilleter dès que je l'ai eu dans les mains car c'est aussi un bel objet.

Gérald Tremblay vit sur le côté nord de la Gaspésie, du côté où les mots se mesurent autant que les gestes. C'est pourquoi sa Parole est une poésie incarnée et enracinée dans des mots vrais, denses et vécus. Il nous prévient en début de livre, dans sa préface:

"On ne parlera pas politique

On parlera poésie

C'est de pays qu'il s'agit

C'est de chez-nous

La Gaspésie". 